\title{
A GUIDING TOOL IN UNANI TIBB FOR MAINTENANCE AND PRESERVATION OF HEALTH: A REVIEW STUDY
}

\author{
Farkhunda Jabin \\ *Guest Faculty, Dept. of Hifzane Sehat Wa Samaji Tib (Preventive and Social Medicine) Faculty of \\ Unani Medicine, Aligarh Muslim University, Aligarh, 202 002, (U.P.), India. \\ E-mail: far.khun.da@hotmail.com
}

\begin{abstract}
Unani Tibb is a holistic traditional system of medicine. Ever since 1976, WHO has adopted its policy of promoting traditional medicine, Unani Medicine has enjoyed an upsurge of interest, especially in India, where it has been practiced as one of the Indian systems of medicine. Ali et al (2007) opined that "in Tibb, 'temperament' is a notion of primary importance, though a difficult theory as it indicates the properties of an atom, a molecule, a cell, a tissue, an organ and human body as a whole". Temperament of a person represents its physical constitution and tendencies. It is believed in Tibb that imbalance in temperament predisposes human body to various diseases by producing a biotic imbalance with in body. Causes of initial imbalance in temperament lies in more subtle elements of life like air, water, food, rest, activity, work, evacuation of wastes, sleep etc. To quote Bhika (2006a) "health can be preserved and maintained as long as overall quality of humours is in harmony with overall quality of the temperament of the individual and humoural balance is influenced by lifestyle factors." Hence temperament acts as a guiding force for maintenance and preservation of individuals' health.
\end{abstract}

Key Words: Temperament, Unani, Tibb, Humour, Lifestyle factors.

\section{Introduction}

Unani Tibb is one of the ancient systems of medicine of which many believe modern system of medicine has evolved. Greek/ Ionian is translated as Unani and Medicine as Tibb in Arabic. It can be defined as that system of Greek medicine which developed during Arab civilization. (Niamatullah, 1973) observes that "Muslims still call it Unani gratefully acknowledging its place of origin whereas European historians would call it Arabic Medicine or Geeko-Arabic medicine”. Presently, it has been widely practiced in India and Indian subcontinent (AYUSH, 2010). Tibb has never been static and journeyed through various continents and chronology, Ibn-e-Sina, popularly known a Avicenna (980-1037AD) is considered as immortal along with other scholars who contributed to the system such as Aesculapeus ( $8^{\text {th }}$ century BC), Pythagorous (580-489 BC), Aristotle (384-322 BC), Hippocrate (460-370 BC), Discorides (70 AD) Galen (131-210 AD), Ibne Raban Tabari (810-895 AD), Abu Bakar Zarakariya Razi popularly known as 'Rhazes’ (865-925 AD), Jabir bin Hayyan (717-813 AD). Ibn-e-Sina is the author of world known famous book on fundamental treatise of Unani Medicine in five volume populary known as Al-Qanoon-fit-Tibb (Canon of Medicine).In India, Siddiqui (1981) pointed out that Unani medicine was introduced in $1351 \mathrm{AD}$ by Arabs and flourished under the patronage of Mughal Emperors among the masses and spread all over the country. It suffered a setback during the British rule but soon regained its momentum by endless efforts of Nizam of Hyderabad, Azizi family of Lucknow and Sharifi family of Delhi. At present Unani system of medicine has now been regarded and recognized as one of the Indian systems of medicine and forms an integral part of national healthcare delivery system (Siddiqui,2009a)

\section{Concept of Temperament in Unani Tibb}

It is assumed that all things in nature are composed of four primary elements i.e. fire, air, water and earth. (Azmi 1995). It does not mean that the numbers of elements in nature are four. In fact, they represent the basic division of matter which is found in universe. Each of them are associated with compound qualities, fire element is hot and dry, air is hot and moist, water is cold and moist and earth is cold and dry (Encyclopaedia Britannica, 1974). Hence temperament may be defined as "the quality which is produced by actions and reactions of opposite qualities of elements, which are broken in smaller particles in order to facilitate the mixing of all particles. When those components interact among themselves by virtue of their respective powers (qualities), a condition is produced, which is found in equal proportions in all components of the elements” (Sina, 2010). In other words 'constitution' of any matter is tantamount to 'temperament'. Every organism and matter as a whole is furnished with a temperament upon which their properties and functions of life depend. Drugs and foods are classified according to temperament, representing unique structural composition. But the temperament of human body is determined by humours (body fluids) which themselves are composed of different elements. 


\section{Temperament of Human Body}

Hippocrate said that the human body is composed of three parts i.e.(i) Solid known as organs (aza), (ii) Liquid known as humours (akhlat) and (iii) Gas known as pneuma (arwah) (Masihi, 2008). Scholars of the Unani Tibb has mentioned the humours and their associated qualities as: (i) Dam (blood) as 'hot and moist'; (ii) Safra (yellow bile) as 'hot and dry'; (iii) Balgham (phlegm) as 'cold and moist' and; (iv) Sauda (black bile) as 'cold and dry' (Shah, 2007).Galen, one of the ancient Unani physician, used to refer word temperament to bodily dispositions, which determined a person's susceptibility to particular diseases as well as behavioral and emotional inclinations (Wikipedia, 2011). Hence word temperament is often used in psychological sense but in medical sense it implies the blend of humours (biological constitution). Accordingly temperament is created by mixing humours and is named after dominant humour in the body. When a person is said to have a hot temperament it means dam humour has stood dominant over other humours. In the same way cold humour signifies the dominance of sauda, dry temperament demonstrate the dominance of safra, and moist temperament shows the dominance of phlegm.On this assumption, human temperament is also termed as sanguineous (blood), choleric (yellow bile), phlegmatic (balgham), and melancholic (black bile)( Ahmad, 1980).

\section{Temperament and Health}

When humours are normal in quantity and quality and well mixed than condition of eukrasia (in temperament) prevails, man remains healthy. When however, as a result of disturbances, the balance is upset, dyscrasia prevails and individual becomes sick (Henry, 1973). Majusi (2010) stated that the humours mixed in balanced proportions, both in quantity and quality, constitute health and their disproportionate and irregular distribution in quantity or quality, causes disease. This equilibrium is controlled by an innate power of the body called Tabiat. But the state of humours in the body is also affected by external factors like, diet, and environmental influence etc. Tibb recognizes six essential factors (also called lifestyle factors) which affect the composition of temperament (humour) of human body. They are: (i) ambient air; (ii) food and drink; (iii) physical activity and rest; (iv) emotions and feelings; (v) sleep and wakefulness; (vi) retention of fluids and evacuation of wastes. (Siddiqui, 2009b)

Tibb considers the approach towards health and reinforcement of health should be individualistic and based on temperament. Health maintenance and disease prevention can be advocated by knowing constitutional type, knowing how to eat, live and medicate properly. Drugs are also prescribed in relation to the temperament of person. A person having a particular temperament is not prescribed a drug of the same temperament.

\section{Maintenance and Preservation of Health according to Temperament}

Too much of dominant quality associated with a temperament will produce negative effect, is an important guideline for maintenance and preservation of health e.g. Choleric (safra) will be affected negatively by lifestyle factors which increase heat and dryness, as quality associated with this temperament is heat and dryness (Bhika, 2006b). According to the temperament of an individual, following are some of the concrete steps, if adhered to, for the maintenance and preservation of health:

SANGUINE TEMPERAMENT (dam/ cold and moist)

Identification: They have oval face and head moderate frame with more muscular tissues than fat, joints are well formed and prominent, and hairs of head are thick and luxuriant. They are pleasantly warm to touch. They have good appetite, balanced and sound sleep, and good faculty of judgement. An optimistic positive mental outlook, they are persuasive extrovert, have good social skills. They have romantic nature, like to travel, play games and distractions, confident, poised, graceful and enthusiastic. In order to remain healthy, they should adopt the following lifestyle factors:

Air: Avoid staying for long in hot and moist air. They can tolerate cold easily.

Food and Drinks: They should preferably drink cold water and avoid excessive sugar, rich fatty foods and meat consumption. Moderation in eating habits is essential to avoid the mal-nourishment of the body.

Physical Activity: Inadequate rest and strenuous activities should be avoided. Light weight training and aerobics for 15-20 minutes are suitable for this temperament.

Sleep and Wakefulness: 6-7 hour of sound sleep is essential, taking sleep more than 8 hours will be harmful.

Emotions and Feelings: Excessive excitement, worry, anger or emotional excesses for kind of temperament should be avoided, deep and breathing exercise is beneficial.

Retention of fluids and Evacuation of wastes: High fibre in diet in order to maintain regular bowel habits is essential, increase water intake in order to maintain regular functioning of kidney. Cupping or donating blood twice a year (preferably in spring or summer) is recommended.

Imbalance predisposes them to diseases like uraemia, gout, diabetes, high cholesterol, reduced intestinal motility, respiratory catarrh, asthma, genito-urinary disorders hypersensitivity, and capillary congestion.

\section{CHOLERIC TEMPERAMENT (safra /hot and moist)}

Identification: They have sharp angular features, broad jaw, medium/lean built with flushed complexion, brilliant penetrating eyes, prominent veins, light coloured hairs, often curly and thin, good digestion, sharp and quick appetite. Restless and disturbed sleep, often tend to wake up early or in the middle of the night. They are bold, daring, and dominant 
and have brilliant intellect but they are impatient, irritable, and short tempered. Often they turned into fearless and rebellious leaders.

Air: Increase in the temperature of air affects them the most, exposure to sun or hot climate should be avoided. They should live in cool, fresh and properly ventilated environment.

Food and Water: They should avoid salt, salty foods, fats, fried foods, vinegar, sour or fermented foods, excessive hot spices, chillies, excessive beef and red meat and should include milk and dairy products and ice cold drinks in their diet.

Physical Activity: They should avoid excessive movement and strenuous exercise, time of exercise should be early in the morning or late in the evening.

Sleep and Wakefulness : A good night sleep for 6-8 hours is essential for such type of temperament as it is hard to get sleep, forty-five minutes rest after lunch is also beneficial.

Emotions and Feelings: Extreme emotions of anger, irritability, excessive talkativeness, and suppression of anger are emotional extremes for this kind of temperament.

Retention of Fluids and Evacuation of Wastes: Drink plenty of water in order to eliminate heat and toxins, laxatives are also beneficial.

Imbalance predisposes them to fevers, infections, rashes, urticaria, hyperacidity, headaches, migraines, eyestrain, hypertension, stress, and cardiovascular disorders.

\section{PHLEGMATIC (phlegm / cold and moist)}

Identification : They have round face with full cheeks, large moist eyes, have medium to large frame, more fatty tissue than muscular tissue , bones are well covered. Veins are less visible, plump and they have delicate soft skin. They are calm, have sentimental subjective thinking, emotional, sensitive, tends to be religious, their mind is foggy, and slow.

Air: Cold air negatively affects them hence air conditioners and cold and wet environment should be avoided.

Food and Drinks: Milk and dairy products, cheese, refined sugar and starches, glutinous foods like wheat and flour cold foods, ice-cold foods, and drinks, creamy rich foods should be avoided. But they can easily digest meat, hot and spicy foods even in excess.

Physical Activity: Lack of exercise and unnecessary rest during day time especially one hour before sunset should be avoided. They should indulge in strenuous exercise for longer duration. Aerobics or weight training is beneficial for them.

Sleep and Wakefulness: A sleep for 6-7 hours is sufficient, more than this will harm them. They should get up early in the morning and avoid sleep after sunrise.

Feelings and Emotions: Fear, shyness, depression are the emotional excesses for this temperament which should be managed accordingly.

Retention of Fluids and Evacuation of Wastes: Sweating is beneficial, it should never be suppressed and laxatives are also beneficial.

Imbalance predisposes them to phlegm congestion, water retention, oedema, slow digestion, weight gain obesity, poor venous circulation, tendency towards depression.

\section{MELANCHOLIC (sauda / cold and dry)}

Identification: They have rectangular face or head, small beady eyes with sunken hollow cheeks, they are lean and thin, and have prominent bones, joints and veins, hairs are dark, thick and straight. They have less body and facial hairs. Their touch is dry, leathery and cool. Their appetite is variable or poor. They have difficulty in falling asleep. They are analytical, detail oriented, retentive faculty of mind is well developed; they tend to be perfectionist, are practically efficient and dependable. Air: Dry air negatively affects them. They should avoid staying in cold and dry environmental conditions for long. They need to be protected in dry weather conditions. Seashore and coastal areas are beneficial for their health.

Food and Drink: Melancholic should avoid old, dry and stale food, excessive beans, nuts, astringent foods, peanuts, tomatoes, eggplant (brinjal), rancid fats and nuts are harmful for them even in small quantities. Tea coffee, artificially flavoured drinks should be avoided.

Physical Activity: Moderate and light exercise for short durations are best suited for such temperaments; especially walk for 15 minutes after dinner.

Sleep and Wakefulness: They should go to bed early for 6-8 hours night sleep. They are more prone to insomnia, $10-15$ minutes break after lunch is beneficial.

Emotions and Feelings: Feeling of loneliness, depression and grief can have much more negative influence especially if prolonged or excessive.

Retention of Fluids and Evacuation of Wastes: They should prevent over drying by applying moisturizers on their skin. Drink at least 2-3 litres of water. Bodily wastes like urine and stool should never be suppressed.

Imbalance may cause anorexia, poor appetite, constipation, colon and gas related ailments, wasting, emaciation and dehydration, arthritis, neuromuscular disorders, and anxiety.

\section{Conclusion}

Recent shift in modern medicine has been observed from treatment, towards the maintenance of health. But Unani Tibb from its advent has defined maintenance of health as one of its prime objectives. In Tibb, knowing one's individual constitutional nature and temperament is the primal step towards path of health and healing. This basic notion guides how to stay healthy and avoid diseases. It is equally beneficial for the physician for taking care of his patients and prescribing drugs accordingly. 


\section{References}

1. Ahmad, S. I. (1980). Introduction to Al-Umoor-Al-Tabi’yah Principles of Human Physiology in Tibb , Saini Printers Pahari Dhiraj, Delhi-6, India , pp. 57-58.

2. Ali, S. M. ,Islam, R. , Alam, M. (2007). A Scientific Co-relation between Blood Groups and Temperaments in Unani Medicine, Indian Journal of Traditional Knowledge 6: 319-323.

3. AYUSH, (2010). AYUSH Government of India Retrieved from the link http://indianmedicine.nic.in/index3.asp?sslid=133\&subsublinkid=14\&lang=1 on 7 April 2010 at 17:15 IST.

4. Azmi, A.A. (1995). Basic Concepts of Unani Medicine A Critical Study. Jamia Hamdard, Hamdard Nagar, New Delhi ,India : 5-6.

5. Bhika, R. (2006a, b). Learning with Tibb. Ibn Sina Institute of Tibb, South Africa :13-14.

6. Encyclopaedia Britannica (1974). $15^{\text {th }}$ edition. 3: 846 .

7. Henry, E.S. (1973).Theories and Philosophies of Medicine. Institute of History of Medicine And Medical Research (IHMMR). Hamdard Nagar, New Delhi-110062,India, pp.182.

8. Majusi, A. A. (2010). Kamil al Sana. Urdu translation by Ghulam Husain kanturi. Idara kitab-us-shifa,Daryaganj New Delhi-2, India, pp. 61-62

9. Masihi, A.S. (2008). Kitab al Mia’t, Urdu translation by Central Council for Research in Unani Medicine. Institutional Area apposite D block Janakpuri, New Delhi-110058 India pp. 101

10. Niamatullah, S (1973). Theories and Philosophies of Medicine. Institute of History of Medicine And Medical Research (IHMMR) .Hamdard Nagar, New Delhi-110062, India pp. 83.

11. Shah, H.M. (2007). The General Principles of Avicenna’s Canon of Medicine. Idara Kita-us-Shifa. New Delhi, India, pp. 37-42.

12. Siddiqui, K. (2009a, b). Unani Medicine in India. Central Council for Research in Unani Medicine(CCRUM) ,Institutional area Janakpuri , New Delhi-110058, India pp. 5- 6.

13. Siddiqui, T. (1981). Unani Medicine in India-1524to 1605AD. Indian Journal of History of Science .16 (1): 22-25.

14. Wikipedia,2011 humorism retrieved on7april2011 at 17:00 ISTfrom the link http://en.wikipedia.org/wiki/Four humours

15. Sina, I. (2010). Al-Qanoon Fil Tibb.Urdu Translation by Ghulam Hussain kanturi ,Aijaz publishing house, Daryaganj New Delhi -2,India . (1):38 